\title{
Biological Evaluation of Nitrile Containing Ru(II) Polypyridyl Complexes as Potential Photodynamic TherapyAgents
}

\author{
C. Mari, ${ }^{\mathrm{a}}$ R. Rubbiani ${ }^{\mathrm{a}}$ and G. Gasser ${ }^{\mathrm{a},{ }^{*}}$ \\ ${ }^{a}$ Department of Chemistry, University of Zurich, Winterthurerstrasse 190, 8050 Zurich, Switzerland.E-mail: gilles.gasser@chem.uzh.ch \\ WWW: www.gassergroup.com
}

\begin{abstract}
The use of Ru complexes in light-mediated treatment of cancer (i.e. Photodynamic Therapy - PDT) has recently become extremely relevant with the entry into clinical trials of the first complexof this class against bladder cancer. Herein, we report on the potential application as PDT agents of two inertRu(II) polypyridyl complexes bearing a nitrile containing dppz ligand and two bipy or phenancillary ligands for $\mathbf{1}$ and $\mathbf{2}$, respectively $\left(\mathrm{dppz}=\right.$ dipyrido[3,2-a:2',3'-c]phenazine,bipy $=2,2^{\prime}$-bipyridine, phen $=1,10$ phenathroline).More specifically, a full characterization of the novel compound $\mathbf{2}$ was first performed. The distribution coefficients $(\log \mathrm{D})$ and ${ }^{1} \mathrm{O}_{2}$ quantum yields in two solvent systems and at two irradiation wavelengths were then determined for both compounds. The phototoxicity of complexes $\mathbf{1}$ and $\mathbf{2}$ was evaluated on cervical cancer HeLa cells and on non tumorigenic retinal pigment epithelial (RPE1-hTERT) cells. None of the complexes was found to be phototoxic.In vitro fluorescence microscopy indicated a scarce cellular uptake for $\mathbf{2}$. The lack of biological activity for complexes $\mathbf{1}$ and $\mathbf{2}$ highlightsthat more investigations are required in order to understand the relationship between structure and biological activity for this class of compounds.
\end{abstract}

\section{Introduction}

The application of ruthenium complexes as biologically active compounds was thoroughlyinvestigatedin the last decades. Two $\mathrm{Ru}(\mathrm{III})$ complexes are currently undergoing Phase II clinical trials as anticancer agents(i.e. NAMI-A and KP-1339) and a Ru(II) organometallic complex is under clinical optimization (i.e. RAPTA-C). ${ }^{[1-4]}$ The complexes which are under evaluation are characterized by a mechanism of cytotoxicity based on ligand exchange. Another class of Ru compounds, namely substitutionally inert $\mathrm{Ru}$ (II) polypyridyl complexes, is characterized by favourable photophysicalproperties that make these complexesattractive for applicationssuch as photosensitizers (PSs) in Photodynamic Therapy (PDT) and Photoactivated Chemotherapy (PACT). ${ }^{[5]}$ The use of such complexes for light-mediated treatment of cancer has thoroughly been investigated in the last years. ${ }^{[5]}$ As a highlight of this research, a Ru(II) polypyridyl compound will be soon tested as a PDT agent in the clinics against non-muscle invasive bladder cancer (TLD-1433, Figure 1). ${ }^{[6]}$ Several reasons make this type of compounds usefulin this field of research. For example, they display a strong absorbance in the visible region of the electromagnetic spectrum. Moreover, they are characterized by a reasonably long-lived triplet excited state. This allows for energy transfer to triplet oxygen $\left({ }^{3} \mathrm{O}_{2}\right)$ to form the toxic singlet oxygen $\left({ }^{1} \mathrm{O}_{2}\right)$.However, in this recent and promising research area, there is still a great room for optimization. For example, it would be highly desirable to have novel PSs with enhanced biological activity and/or activation wavelengthsin the PDT window (650-900 $\mathrm{nm}$ ) and/orpossibly $\mathrm{O}_{2}$-independent mechanisms of action.Our group has investigated the potential of Ru(II) polypyridyl compounds as drug candidates over the last years. More specifically, wereported on the activity of Ru(II) polypyridyl complexes as anticancer drug candidates ${ }^{[7,8]}$ as well as PSs in antibacterial $\mathrm{PDT}^{[9]}$ and as $\mathrm{PDT}^{[9,10]}$ orPACT $^{[11,12]}$ agents in cancer treatment. Herein, we report on the biological evaluationoftwoRu(II) complexes of the $\left[\mathrm{Ru}(\mathrm{II})(\mathrm{L})_{2} \mathrm{dppz}-7-\mathrm{CN}\right]^{2+}$ class as potential PDT agents, where 1: $\mathrm{L}=$ bipy and 2: $\mathrm{L}=$ phen(see Figure 1; dppz = dipyrido[3,2-a:2',3'-c]phenazine,bipy $=2,2^{\prime}$-bipyridine, phen $=$ 1,10-phenathroline). 1 was previously synthesized by Gordon et al., who performed photophysicalstudies and DFT calculations on this complex. ${ }^{[13]}$ The biological activity of this compound was, however, never investigated. $\mathbf{2}$ is a novel parent complex of $\mathbf{1}$, bearing two extended aromatic phengroups as ancillary ligands. To characterize the compounds, we measured thedistributioncoefficients $(\log \mathrm{D})$ for both complexes to obtain information on theirbehaviour in biological environments. The 
production of ${ }^{1} \mathrm{O}_{2}$ in two different media (i.e., acetonitrile and PBS buffer) upon irradiation at 420 and 575 nm was also evaluated. Finally, the cytotoxicactivity of the complexes was investigated on two different cell lines, namelynon tumorigenic retinal pigment epithelial (RPE1-hTERT) cells and cervical cancer (HeLa) cells.In addition, the phototoxicity of complexes $\mathbf{1}$ and $\mathbf{2}$ was tested on HeLa cellsupon irradiation at $420 \mathrm{~nm}$. Due to the higher luminescence quantum yields, the cellular localization of 2 was also studied when incubated in HeLa cells.
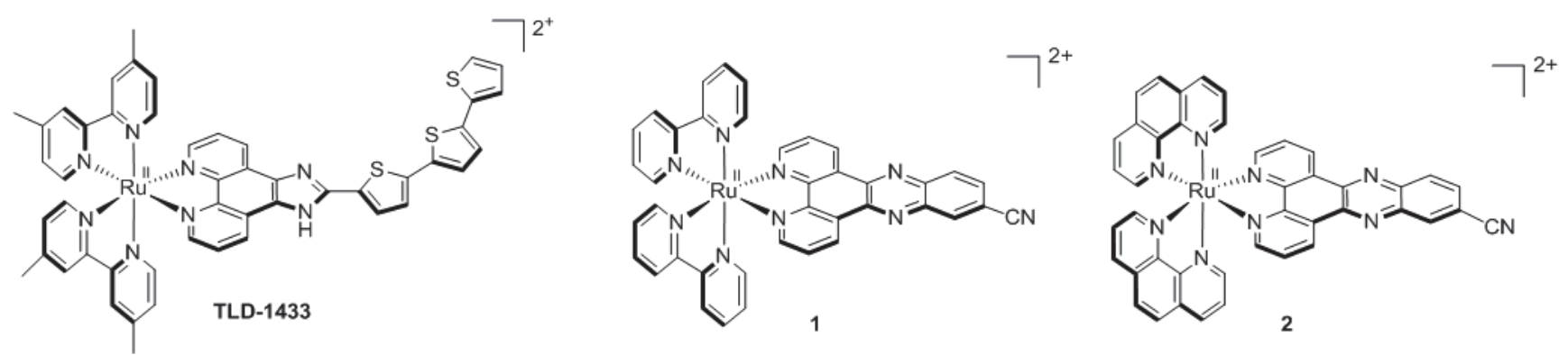

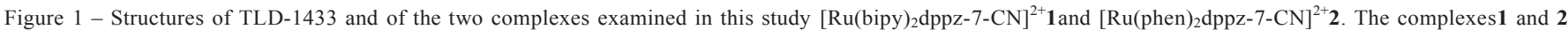
were isolatedas $\mathrm{PF}_{6}^{-}$salt and racemic mixtureof the isomers.

\section{Experimental Part}

\subsection{Instruments and methods}

All commercial chemicals were used without further purification. ${ }^{1} \mathrm{H}$ and ${ }^{13} \mathrm{C}$ NMR measurements were carried out on Bruker 500 spectrometers and referenced to residual solvent peaks.ESI-MS and R.P. UPLC-MS were performed using a Bruker Daltonics HCT 6000 mass spectrometer. R.P. UPLC-MS spectra were recorded on a Waters Acquity ${ }^{\mathrm{TM}}$ system equipped with a PDA detector and an auto-sampler. R.P. UPLC-MS was performed on an Acquity UPLC BEH C18 column (21.50 x $1.7 \mathrm{~mm})$. The UPLC run (flow rate: $0.6 \mathrm{ml} \mathrm{min}{ }^{-1}$ ) was carried out with a linear gradient of A (double distilled water containing $0.1 \% \mathrm{v} / \mathrm{v}$ formic acid) and $\mathrm{B}$ (acetonitrile): $\mathrm{t}=0 \min , 5 \% \mathrm{~B} ; \mathrm{t}=0.25 \min , 5 \% \mathrm{~B} ; \mathrm{t}=1.5 \min , 100 \% \mathrm{~B} ; \mathrm{t}=2.5 \min , 100 \%$ B. High resolution ESI-MS spectra were recorded using a Bruker ESQUIRE-LC quadrupole ion trap instrument. UV spectra were recorded on a Varian Cary 100 spectrophotometer. Elemental microanalyses were performed on a LecoCHNS-932 elemental analyser. ESI-MS were performed using a Bruker Daltonics HCT 6000 mass spectrometer.UV-A irradiation was performed using a Rayonet RPR-200 photochemical reactor with 6 (for biological evaluations) or 12(for singlet oxygen measurements) bulbs (14W each) and maximum intensity output at $420 \mathrm{~nm}$ and $575 \mathrm{~nm}$. Samples were irradiated in a Starna $\mathrm{GmbH} 3.5 \mathrm{ml}$ fluorescence quartz cuvette (width 1 $\mathrm{cm})$ placed in the centre of the reactor. The light intensity at that spot, measured with an X11optometer (Gigahertz-Optik), was $77.2 \mathrm{~W} \cdot \mathrm{m}^{-2}$ at $420 \mathrm{~nm}$ and $69.3 \mathrm{~W} \cdot \mathrm{m}^{-2}$ at $575 \mathrm{~nm}$. The temperature inside the reactor was $30^{\circ} \mathrm{C}$.In vitro luminescence experiments were performed using a CLSM Leica SP5 microscope.

\subsection{Synthesis of 1}

1 was synthesized as previously reported. All analytical data matchedwhat that previouslyreported. ${ }^{[13]}$

\subsection{Synthesis of 2}

dppz-7- $\mathrm{CN}^{[13]}$ (107 mg, $0.350 \mathrm{mmol}, 1.0$ eq)and $\left[\mathrm{Ru}(\mathrm{phen})_{2} \mathrm{Cl}_{2}\right]^{[14]}(185 \mathrm{mg}, 0.355 \mathrm{mmol}, 1.1$ eq) were suspended in $100 \mathrm{~mL}$ of degassed EtOH/ $\mathrm{H}_{2} \mathrm{O}$ 1/1 solution. The mixture which was refluxed for $3 \mathrm{~h}$ turned red during the reaction. The organic solvent was removed byrotary evaporation and the crude product purified by column chromatography on silica gel with $\mathrm{CH}_{3} \mathrm{CN}_{\mathrm{aq}}$. $\mathrm{KNO}_{3} 0.4$ $\mathrm{M}(10 / 1)$ as the eluent. The fractions containing the product were combined and the eluent was removed on a rotary evaporator. Workup of the reunited fractions after the column: $\mathrm{CH}_{3} \mathrm{CN}(30 \mathrm{~mL})$ was added to the solid residue to dissolve the red product. The white, insoluble solid (excess of $\mathrm{KNO}_{3}$ ) was removed by filtration. The solvent was removed by rotary evaporation and the residue redissolved in water $(40 \mathrm{~mL}) . \mathrm{NH}_{4} \mathrm{PF}_{6}$ was then added to make the complex precipitate as a $\mathrm{PF}_{6}$ salt. The precipitate was collected 
by filtration, washed with water $(20 \mathrm{~mL})$ and diethyl ether $(25 \mathrm{~mL})$ and dried on a vacuum pump, to obtain 2 as a red powder in $62 \%$ yield. ${ }^{1} \mathrm{H}$ NMR $\left(500 \mathrm{MHz}, \mathrm{CD}_{3} \mathrm{CN}\right) \delta(\mathrm{ppm}): 7.62-7.68(\mathrm{~m}, 4 \mathrm{H}), 7.77-7.80(\mathrm{~m}, 2 \mathrm{H}), 8.01-8.02(\mathrm{~d}, 2 \mathrm{H}), 8.13-8.15(\mathrm{~m}, 2 \mathrm{H})$, 8.22-8.23 (m, 2H), 8.25-8.27, (m, 5H), 5.57-8.59 (d, 1H), 8.60-8.64, (t, 4H), 8.93-8.94 (d, 1H), 9.58-9.63 (m, $2 \mathrm{H}) .{ }^{13} \mathrm{C} \mathrm{NMR}(126$ $\left.\mathrm{MHz}, \mathrm{CD}_{3} \mathrm{CN}\right): 116.13,118.67,126.84,126.90,128.38,128.42,129.03,129.04,131.27,132.02,132.04,132.23,133.33,134.59$, $134.79,137.06,137.92,137.98,142.45,142.61,143.10,144.61,148.74,148.81,152.27,152.46,153.91,154.22,155.78,155.92$. ESI-MS (pos. detection mode): $m / z\left[\mathrm{M}-2 \mathrm{PF}_{6}\right]^{2+} 384.7,\left[\mathrm{M}-2 \mathrm{PF}_{6}+\mathrm{TFA}\right]^{2+} 882.2$. ESI HR-MS calcd. for $\left[\mathrm{C}_{43} \mathrm{H}_{25} \mathrm{~N}_{9} \mathrm{Ru}^{2} / \mathrm{z}[\mathrm{M}-2 \mathrm{PF} 6]^{2+}\right.$ 384.5633, found 384.5644; Anal. calcd. for $\mathrm{C}_{43} \mathrm{H}_{25} \mathrm{~F}_{12} \mathrm{~N}_{9} \mathrm{P}_{2} \mathrm{Ru}+\mathrm{CH}_{3} \mathrm{COCH}_{3}$ (\%): C, 49.47; H, 2.80; N, 11.29. Found: C, 49.37; H, $2.61 ; \mathrm{N}, 11.50$. UPLC r.t.:1.05 $\mathrm{min}$.

\subsection{Luminescence quantum yields and lifetimes}

For the luminescence quantum yields measurements, emission spectra were recorded with a Varian Cary Eclipse Fluorescence Spectrophotometer equipped with a Hamamatsu R3896 photomultiplier tube as detector, where the sample temperature can be controlled by a Peltier thermostatic system. Emission spectra for excitation at $440 \mathrm{~nm}$ were corrected for the spectral sensitivity of the detection system by standard correction curves. The emission intensities were normalized to a nominal absorption value of 0.1 . The quantum yield in aerated $\mathrm{CH}_{3} \mathrm{CNwas}$ determined by comparison with the emission of $\left[\mathrm{Ru}(\text { bipy })_{3}\right] \mathrm{Cl} l_{2}$ in aerated water $(\Phi=$ 0.042). ${ }^{[15]}$

Luminescence lifetime measurements were recorded in degassed $\mathrm{CH}_{3} \mathrm{CN}$ using an Edinburgh LP920 Laser Flash Photolysis transient absorption spectrometer with a flashlamp pumped Q-switched Nd:Yag laser (355 nm) as excitation source.

\subsection{Distribution coefficients}

The distribution coefficient of each complex was experimentally determined by using the "shake-flask" methodas previously reported in our group. ${ }^{[10]}$ Briefly, the complexes were dissolved in a $10 \mathrm{mM}$ phosphate buffer (pH 7.01) previously saturated with n-octanol to give about $1 \mathrm{~mL}$ of a solution with a concentration of $50 \mu \mathrm{M}$. The same volume of octanol (previously saturated with $10 \mathrm{mM}$ phosphate buffer) was then added and the solution was shaken 100 times and equilibrated for $4 \mathrm{~h}$. The concentration of the complexes in the aqueous phase was then evaluated by UV/Vis spectroscopy.

\subsection{Singlet oxygen evaluation}

The singlet oxygen measurements were performed using two different methodsas recently reported by our group. ${ }^{[10]}$

Direct evaluation: Phosphorescence measurements were performed on a Fluorolog-3 Spectrofluorometer (JobinYvon Horiba, Model FL3-11) with a $450 \mathrm{~W}$ xenon lamp light source and single-grating excitation and emission spectrometers. For high beam intensity, the excitation slits were set to a maximum value of $29.4 \mathrm{~nm}$. A colored glass filter was placed between the sample and the detector to cut off light below $695 \mathrm{~nm}$. The emission signal was collected at right angle to the excitation path with an IRsensitive liquid nitrogen cooled germanium diode detector (Edinburgh Instruments, Model EI-L). The detector was bias at -160V. The signal-to-noise ratio of the signal detected by the Ge-diode was improved with a lock-in amplifier (Stanford Research

Systems, model SR510) referenced to the chopper frequency of $126 \mathrm{~Hz}$. Data-acquisition was done with DataMax. Samples in aerated acetonitrile were prepared in a luminescence quartz cuvette with an $\mathrm{OD}=0.2$ at the irradiation wavelength. 3 different transmittance filters were used to vary the intensity of the irradiation beam. Intensities of irradiation were plotted versus the areas of the singlet oxygen peaks at $1270 \mathrm{~nm}$ and the slopes of the linear regression was calculated $\left(\mathrm{S}_{\text {sample }}\right)$.

Indirect evaluation: an air-saturated acetonitrile solution containing the complex (OD $=0.1$ at irradiation wavelength), $p$-NOdimethylaniline (RNO) $24 \mu \mathrm{M}$ and imidazole $12 \mathrm{mM}$ or an air-saturated PBS solution containing the complex $(\mathrm{OD}=0.1$ at irradiation wavelength), RNO $20 \mu \mathrm{M}$ and histidine $10 \mathrm{mM}$ were irradiated in a luminescence quartz cuvette at $420 \mathrm{~nm}$ or at 575 $\mathrm{nm}$ in a RPR100 Rayonet Chamber Reactor (Southern New England Ultraviolet Company) complete with 12 lamps, for different time intervals. The absorbance of the solution was then evaluated. Plots of variations in absorbance at $440 \mathrm{~nm}$ in PBS or at $420 \mathrm{~nm}$ 
in acetonitrile $\left(\mathrm{A}_{0}-\mathrm{A}\right.$, where $\mathrm{A}_{0}$ is the absorbance before irradiation) versus the irradiation times for each sample were made and slope of the linear regression calculated $\left(\mathrm{S}_{\text {sample }}\right)$.

As reference compounds, phenalenone $\left(\Phi_{\text {ref }}\left({ }^{1} \mathrm{O}_{2}\right)=95 \% \text { in both solvents }\right)^{[16]}$ and rose bengal $\left(\Phi_{\text {ref }}\left({ }^{1} \mathrm{O}_{2}\right)=75 \%\right.$ in $\mathrm{PBS}$ and $\Phi_{\text {ref }}\left({ }^{1} \mathrm{O}_{2}\right)=65 \%$ in $\left.\mathrm{CH}_{3} \mathrm{CN}\right)^{[17,18]}$ were used in both methods to obtain $\mathrm{S}_{\text {ref. }}$ [1] was applied to calculate the singlet oxygen quantum yields $\left(\Phi_{\text {sample }}\right)$ for every sample:

$\Phi_{\text {sample }}=\Phi_{\text {ref }} * \mathrm{~S}_{\text {sample }} / \mathrm{S}_{\text {ref }} * \mathrm{I}_{\text {ref }} / \mathrm{I}_{\text {sample }}$

$\mathrm{I}=\mathrm{I}_{0} *\left(1-10-\mathrm{A}_{\lambda}\right)$

I (absorbance correction factor) was obtained by [2], where $\mathrm{I}_{0}$ is the light intensity of the irradiation source in the irradiation interval and $A_{\lambda}$ is the absorbance of the sample at wavelength $\lambda$.

\section{$2.7 \quad$ Cell culture}

Human cervical carcinoma cells (HeLa) and non tumorigenic retinal pigment epithelial (RPE1-hTERT) cells were maintained in DMEM (Gibco) supplemented with 5\% and 10\% fetal calf serum (FCS, Gibco) respectively, $100 \mathrm{U} / \mathrm{mL}$ penicillin, $100 \mu \mathrm{g} / \mathrm{mL}$ streptomycin at $37^{\circ} \mathrm{C}$ and $6 \% \mathrm{CO}_{2}$.

\subsection{Cytotoxicity studies}

A fluorometric cell viability assay using Resazurin (Promocell $\mathrm{GmbH}$ ) has been used to compare the cytotoxicity of the Ru(II) complexes in the dark and upon UV-irradiation. HeLa and RPE1-hTERT cells were plated in triplicates in 96-well plates at a density of $4 \times 10^{3}$ and $5 \times 10^{3}$ cells/well in $100 \mu \mathrm{L}$, respectively, $24 \mathrm{~h}$ prior to treatment. Cells were then incubated for $4 \mathrm{~h}$ with increasing concentrations of the compounds. After that, the medium was removed, replaced by fresh mediumand irradiated for 20 min at $420 \mathrm{~nm}\left(9.27 \mathrm{~J}^{-2} \mathrm{~cm}^{-2}\right)$ in a Rayonet Chamber Reactor. After additional $44 \mathrm{~h}$, the medium was replaced by $100 \mu \mathrm{L}$ fresh medium containing resazurin $\left(0.2 \mathrm{mg} / \mathrm{mL}\right.$ final concentration), further incubated for $4 \mathrm{~h}$ at $37^{\circ} \mathrm{C}$ and read on a microplate reader (Spectramax M5, Molecular Devices). The fluorescence of the highly red fluorescent resorufin product was quantified at 590 nm emission with $540 \mathrm{~nm}$ excitation wavelength in a SpectraMax M5 microplate Reader. Light doses were evaluated with a Gigahertz Optic X1-1 Optometer.

\subsection{In vitrofluorescence microscopy}

Cellular localization of 2 was assessed by fluorescence microscopy . HeLa cells were grown on 18 mm Menzel-gläser coverslips at a density of $2 \times 10^{5}$ cells $/ \mathrm{mL}$ and incubated for $4 \mathrm{~h}$ with 2 at a concentration of $100 \mu \mathrm{M}$. Cells were fixed in $4 \%$ formaldehyde solution in PBS, washed with PBS and water and mounted on slides for viewing by confocal microscopy. Fixed cells were viewed on a CLSM Leica SP5 microscope. The target complex was visualized using the red wavelength selection (excitation: 488 nm; emission: $700-800 \mathrm{~nm}$ ) on the CLSM Leica SP5 microscope.Nuclear and Mitochondrial Staining: Co-localization of the complex into the nucleus and into mitochondria was examined by means of MitotrackerGreen FM (Molecular Probes, excitation: 490 nm, emission: $516 \mathrm{~nm}$ ), a mitochondria-specific dye and DAPI (excitation: $358 \mathrm{~nm}$, emission: $461 \mathrm{~nm}$ ). Briefly, a $1 \mathrm{mMMitotracker}$ Green FM stock solution made in DMSO was diluted to $10 \mu \mathrm{M}$ concentration in cell medium. Staining of mitochondria was accomplished by adding a $50 \mathrm{nM}$ final concentration of Mito-tracker Green FM to the culture medium for the last 45 min of ruthenium complex incubation. The medium was removed and cells were fixed in $4 \%$ formaldehyde solution in PBS, washed with PBS and water,before being mounted on slides added with $6 \mu \mathrm{L}$ of DAPI (Invitrogen)for viewing by confocal microscope.

\section{Results and Discussion}

\subsection{Syntheses of the complexes.}

Complex 1 was synthesized as reported previously by Gordon et al. and all analytical data matched with the literature data. ${ }^{[13]}$ For the synthesis of $\mathbf{2}$, the dppz-7-CN ligand, whose preparation was reported by Gordon et al., ${ }^{[13]}$ was reacted with the 
$\left[\mathrm{Ru}(\text { phen })_{2} \mathrm{Cl}_{2}\right]^{[14]}$ metal core to obtain 2 . The identity of the compound was confirmed by ${ }^{1} \mathrm{H}$ and ${ }^{13} \mathrm{C}$ NMR spectroscopy as well as by High Resolution ESI-MS and elemental analysis (see Section 2.3 and SI).

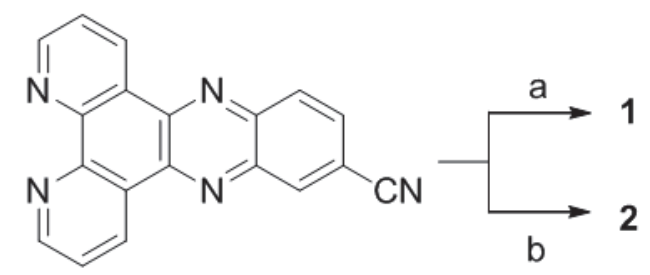

Figure 2 - Synthetic procedures for 1 and 2. a) [ $\left.\mathrm{Ru}(\text { bipy })_{2} \mathrm{Cl}_{2}\right], \mathrm{EtOH}: \mathrm{H}_{2} \mathrm{O}$ 1:1, o.n., reflux. b)[Ru(phen) $\left.{ }_{2} \mathrm{Cl}_{2}\right], \mathrm{EtOH} \mathrm{H}_{2} \mathrm{O} 1: 1,3 \mathrm{~h}, \mathrm{reflux}$.

\subsection{Photophysical characterization}

UV/Vis spectra were recorded in $\mathrm{CH}_{3} \mathrm{CN}$ and in PBS buffer ( $\mathrm{pH}$ 7.01) and the data are reported in Table1 and Figure S6. Both complexes present the same absorption profile, which is typical for the Ru(II) polypyridyl class bearing a dppz ligand. The highest energy band originatesfrom a ligand centered transition. The other bands have a lower intensity. In the 360-370 nm area, the bands are attributed to the ${ }^{1} \pi-\pi^{*}$ transition, whereas at $440-442 \mathrm{~nm}$ it is possible to see the bandoriginated from the ${ }^{3}$ MLCT transition, as expected for this type of complex. The emission spectra were recorded in air equilibrated $\mathrm{CH}_{3} \mathrm{CN}$ and the maximum, together with the emission quantum yields for both compounds, arelisted in Table1. We could reproduce the very low luminescence quantum yield value (i.e. around $0.2 \%$ ) already reported for 1 by Gordon. ${ }^{[13]}$ For complex 2 , on the other hand, a quantum yield of about $2 \%$ was determined, well in the range of previously reported compounds. ${ }^{[10]}$ Lifetimes of the excited state for complexes $\mathbf{1}$ and $\mathbf{2}$ were also evaluated in degassed $\mathrm{CH}_{3} \mathrm{CN}$ and are reported in Table 1.Lifetime of 1 was too short to be detected ( $<15$ ns, which is the detection limit of the instrument), as reported also previously for this compound. ${ }^{[13]}$ For 2 , the estimated excited state lifetime was around 20 ns. The distribution coefficient between octanol and PBS (LogD) was evaluated for both complexes using a method previously applied in our group for $\mathrm{Ru}(\mathrm{II})$ complexes. This parameter provides information on the lipophilicity of a compound and on its behavior in a biological environment. The variation of the ancillary ligand from bipy to phen is predicted to increase the lipophilicity of the system. As expected, 2exhibited a less negative LogD value than 1. Overall, the lipophilicity of these complexes follows the same trend reported previously for similar compounds in our group. ${ }^{[12]}$

\subsection{Singlet oxygen production}

The production of ${ }^{1} \mathrm{O}_{2}$ was investigated using two different methods, namely a direct and an indirect method, already exploited in our group for such a study on similar compounds. ${ }^{[10]}$ The direct method relies on the detection of the luminescence of ${ }^{1} \mathrm{O}_{2}$ generated upon irradiation of a solution of the complex. This method has obviously the advantage to directly measure ${ }^{1} \mathrm{O}_{2}$. However, the sensitivity of this method is affected by the environment in which the experiment is performed. As an example, the sensitivity of this method in aqueous media is normally very low due to the very short lifetime of ${ }^{1} \mathrm{O}_{2}$ in this solvent. ${ }^{[19]}$ The sensitivity also depends on the characteristics of the instrument. For example, with our set-up, we could only detect quantum yields above $24 \%$ in $\mathrm{D}_{2} \mathrm{O}$ since lower ${ }^{1} \mathrm{O}_{2}$ production gives a signal with a quality, which is not good enough for further elaboration. ${ }^{[20]}$ Also in this case, the amount of ${ }^{1} \mathrm{O}_{2}$ generated by both complexes upon irradiation at both 420 and 575 nm was not sufficient to produce a peak detectable with this apparatus.In the indirect method, ${ }^{1} \mathrm{O}_{2}$ is trapped as an adduct formed by interaction with histidine or imidazole (depending on the solvent). This adduct is then quenching the absorbance of a reporter molecule ( $p$-NO-dimethylaniline). This method was reported to have in some cases a lower selectivity for ${ }^{1} \mathrm{O}_{2}$ among the other ROS, when compared with the direct one, which can sometimes bring to overestimation of the ${ }^{1} \mathrm{O}_{2}$ quantum yield. ${ }^{[21]}$ However, the possibility to use this detection system in aqueous environment makes it very appealing when the compounds tested are designed for biological application. Furthermore, thanks to the rapid trapping of ${ }^{1} \mathrm{O}_{2}$ by the histidine derivative, it possible to characterize also compounds with low ${ }^{1} \mathrm{O}_{2}$ quantum yield, contrary to the direct method. The quantum yield of ${ }^{1} \mathrm{O}_{2}$ production was evaluated with this method upon illumination at 420 and $575 \mathrm{~nm}$ in $\mathrm{CH}_{3} \mathrm{CN}$ and in PBS (pH 7.01) and the results are reported in Table 1. Phenalenone was used as reference for 420 


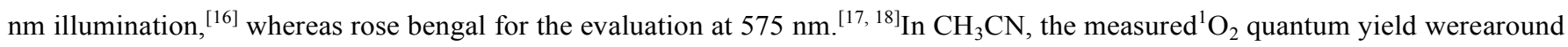
$20 \%$ upon irradiation at $420 \mathrm{~nm}$ for both complexes. At $575 \mathrm{~nm}$ irradiation, 2 had a $\mathrm{O}_{2}$ quantum yield of $14 \%$, whereas 1 one of $11 \%$. In PBS, however, the values were $<1 \%$ for 1 and around $2 \%$ for 2 . This behavior is due to the so-called "light-switch effect" that characterizes this class of compounds. This solvent dependency in ${ }^{1} \mathrm{O}_{2}$ generation was already reported by our group for similar complexes. These values are sensibly lower when compared with the ones measured for complexes with very similar structurepreviously reported by us. ${ }^{[10]}$ In that study, $\left[\mathrm{Ru}(\mathrm{II})\left(\text { bipy }{ }_{2} \mathrm{dppz}\right]^{2+}\right.$ based complexes with functional groups in position 7 , exposed to the same irradiation conditions as the ones used in the present study, were producing ${ }^{1} \mathrm{O}_{2}$ with quantum yields from $50 \%$ up to $99 \%$. On the other hand, these results do not come as a full surprise, due to the short excited state lifetime of the compounds, which is well in accordance with their low ${ }^{1} \mathrm{O}_{2}$ quantum yields. This comparison is clearly highlighting how a small chemical modification on a complex (the variation of a functional group on the dppz ligand) can strongly influence the energetic levels of the compound and significantly modify its photophysical properties.

Table 1 - Electronic characterization, distribution coefficients and ${ }^{1} \mathrm{O}_{2}$ production for $\mathbf{1}$ and $\mathbf{2}$

\begin{tabular}{|c|c|c|c|c|c|c|c|c|}
\hline \multirow{3}{*}{ Complex } & \multirow{3}{*}{$\mathrm{UV}$-Vis $\lambda / \mathrm{nm}\left(\varepsilon / \mathbf{M}^{-1} \mathrm{~cm}^{-1} \times 10^{-3}\right)$} & \multirow{3}{*}{$\begin{array}{c}\text { Emission }^{\mathrm{a}} \\
\lambda / \mathbf{n m}\left(\Phi_{\mathrm{em}}\right)\end{array}$} & \multirow{3}{*}{$\begin{array}{l}\text { Lifetimes } \\
\text { (ns) }\end{array}$} & \multirow{3}{*}{$\log D^{c}$} & \multicolumn{4}{|c|}{$\Phi\left({ }^{1} O_{2}\right)$ - Indirect method } \\
\hline & & & & & \multicolumn{2}{|c|}{$420 \mathrm{~nm}$} & \multicolumn{2}{|c|}{$575 \mathrm{~nm}$} \\
\hline & & & & & $\mathrm{CH}_{3} \mathrm{CN}$ & PBS & $\mathrm{CH}_{3} \mathrm{CN}$ & PBS \\
\hline 1 & $\begin{array}{l}\mathrm{CH}_{3} \mathrm{CN}: 279(125.1), 364(20.7), 373(21.3), 440(20.0) \\
\text { PBS: } 280(127.8), 362(22.2), 376(22.1), 442(20.4)\end{array}$ & $743(0.2 \%)$ & $<15^{\mathrm{b}}$ & -1.02 & $20.7 \%$ & $<1 \%$ & $11.1 \%$ & $<1 \%$ \\
\hline 2 & $\begin{array}{l}\mathrm{CH}_{3} \mathrm{CN}: 265(147.9), 374(26.8), 437(24.8) \\
\text { PBS: } 264(133.1), 377(25.6), 438(22.0)\end{array}$ & $742(1.9 \%)$ & 20.1 & -0.51 & $20.1 \%$ & $2.5 \%$ & $14.0 \%$ & $1.6 \%$ \\
\hline
\end{tabular}

a-Emission spectra recorded in air equilibrated acetonitrile. ${ }^{\mathrm{b}}-$ The signal was too low to be detected. ${ }^{\mathrm{c}}-$ Distribution coefficients between octanol and PBS (pH 7.01).

\subsection{Phototoxicity}

The cytotoxic effect of $\mathbf{1}$ and $\mathbf{2}$ was evaluated on cancerous HeLa cells and non tumorigenic RPE1-hTERT, upon 4 h incubation with the complexes, followed by media replacement and $44 \mathrm{~h}$ of recovery. Both complexes were found to be non toxic up to the highest concentration tested in this work $(100 \mu \mathrm{M})$. The phototoxicity of bothcomplexes was then evaluated on HeLa cells, which were incubated with the compounds for $4 \mathrm{~h}$, followed by media replacement and light irradiation at $420 \mathrm{~nm}$ with light dose of 9.27 $\mathrm{J}^{\mathrm{cm}}{ }^{-2}$. This wavelength was chosen because of the higher generation of ${ }^{1} \mathrm{O}_{2}$ thatwas detected at this wavelength (i.e., compared with $575 \mathrm{~nm}$ ). Upon $44 \mathrm{~h}$ recovery, the viability of cells was determined using theresazurin assay. Unfortunately, for both compounds, no phototoxic effect was observed up to the highest concentration used in this study (100 $\mu \mathrm{M})$. Once again, the difference between these resultsand the ones we obtained previously for similar $\mathrm{Ru}(\mathrm{II})$ polypyridyl complexes in the same biological conditions is striking. ${ }^{[10]}$ It is interesting to note how a very small modification in the structure of such compounds (i.e., the variation of the functional group appended on the dppz ligand) can affect so deeply its photochemical and biological behavior.

\subsection{In vitro fluorescence evaluation}

The ability of a compound to permeate the phospholipid bilayer that composes the cellular membrane and accumulate inside the cells can have a strong impact on its biological activity. Therefore we decided to investigate the uptake of 2 in HeLa cells, thanks to its emissive properties. HeLa cells were incubated for $4 \mathrm{~h}$ with 2 and co-staining with DAPI (DNA staining agent) and MitoTracker Green (mitochondria-specific dye) was performed in order to assess the compound localization. The results are reported in Figure 3. 


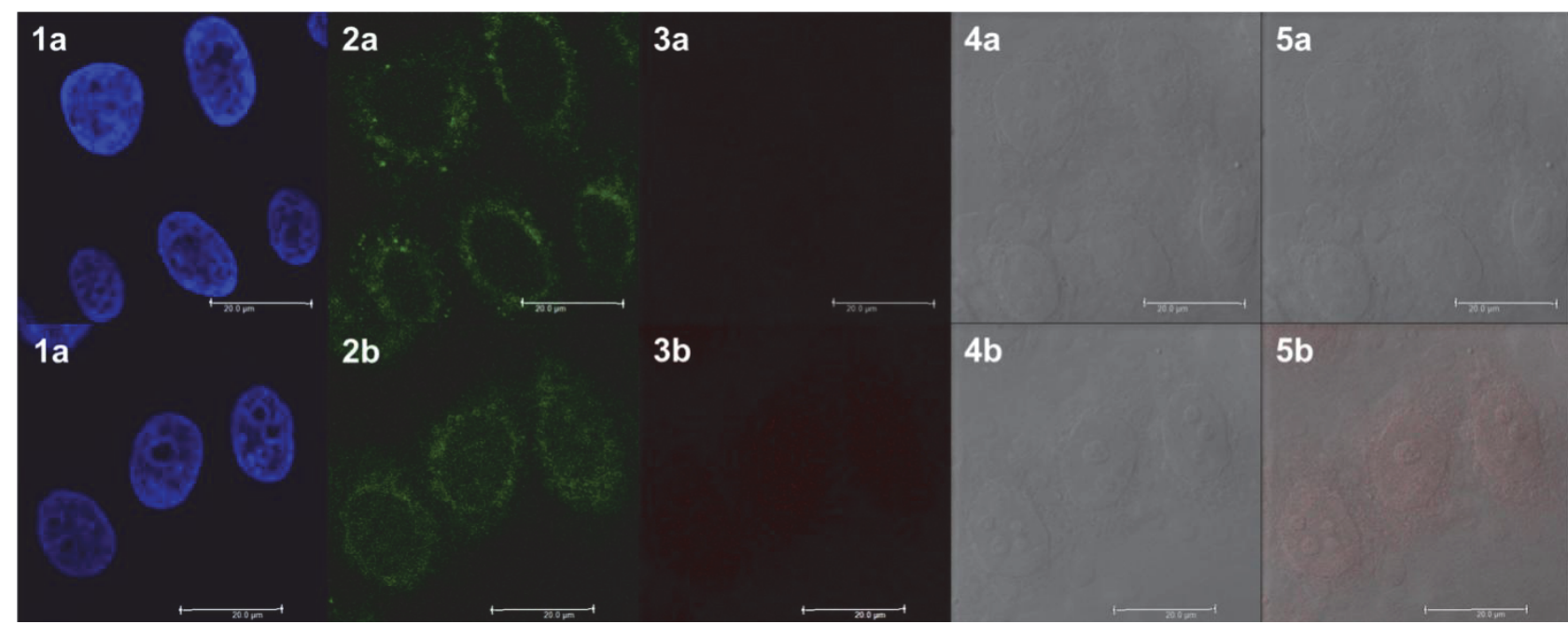

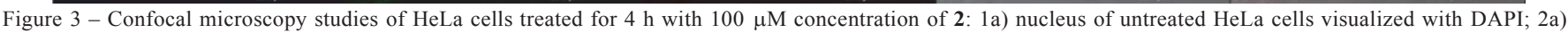

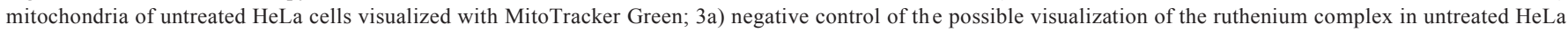

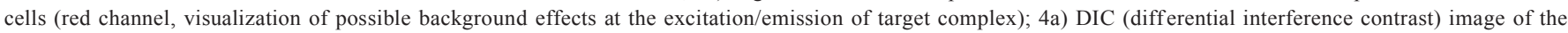

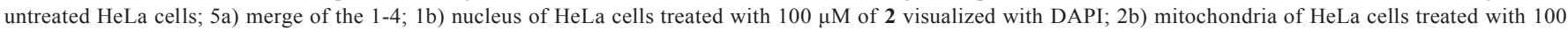

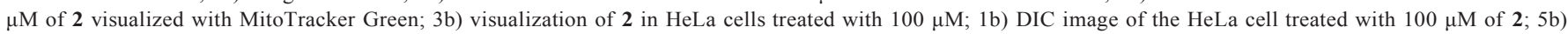
merge of 1-4; the legend bar represents $20 \mu \mathrm{m}$.

In section $3 \mathrm{~b}$ of Figure 3 it is possible to see a vague luminescence of 2 spread all over the cytoplasm of the cells. This finding, together with thelack of cytotoxic activity of this complex, mightsuggests a scarce cellular accumulation for 2 . However, to fully ascertain this assumption, a quantification of the cellular uptake by atomic absorption spectroscopy (AAS) or by inductively coupled plasma mass - spectrometry (ICP-MS) would be necessary. ${ }^{[10,22]}$

\section{Conclusions}

In this paper, we reported on the potential application as PDT agents of two Ru(II) complexes (1 and 2 ) bearing a nitrile substituted dppz ligand andbipy or phen as ancillary ligands, respectively. The synthesis and characterization of $\mathbf{1 h a s}$ previouslybeen reported. However, it has neverbeen characterized from a biological point of view. On the contrary, the synthesis of $\mathbf{2}$ is reported herein for the first time. $\mathbf{2}$ is characterized by a higher luminescence quantum yields than $\mathbf{1}$ ( $2 \%$ vs $0.2 \%$ ). However, their efficacy in light-mediated production of ${ }^{1} \mathrm{O}_{2}$ is comparable with $\Phi\left({ }^{1} \mathrm{O}_{2}\right)$ in $\mathrm{CH}_{3} \mathrm{CN}$ of about $20 \%$ upon irradiation at 420 nm and of about 10\% upon irradiation at $575 \mathrm{~nm}$. As required for PDT applications, incubation of HeLa or RPE1-hTERT with the complexes in the dark did not produce any toxic effect. Indeed, the cytotoxicity of the PS itself is an undesirable characteristic, limiting the possibility to have a full control of the toxicity of the system. However, upon irradiation at $420 \mathrm{~nm}($ light dose $=9.27$ $\mathrm{J} \mathrm{cm}^{-2}$ ), HeLa cells incubated with the compounds did not show any signs of cell deathat the higher concentration used in this study $(100 \mu \mathrm{M})$. Of note, using the same experimental conditions applied in this study, two compounds previously reported by our group, namely $\left[\mathrm{Ru}(\mathrm{II})(\text { bipy })_{2} \mathrm{dppz}-7-\mathrm{NH}_{2}\right]^{2+}$ and $\left[\mathrm{Ru}(\mathrm{II})(\text { bipy })_{2} \text { dppz-7-OMe }\right]^{2+}$ displayed a strong phototoxic effect. ${ }^{[10]}$ Furthermore, we investigated the ability of compound 2 to penetrate cellular walls and accumulate in HeLa cells, owing to its higher luminescence quantum yields. Only a vague luminescence was detectable spread all over the cytoplasm, which can be an indication of a very poor uptake of the compound in this cells.However, it is necessary to consider that luminescence microscopy can give sometimes deceiving results when applied to complexes characterized by a light switch behavior. As recently reported for the $\left[\mathrm{Ru}(\mathrm{II})(\text { bipy })_{2} \mathrm{dppz}-7-\mathrm{NH}_{2}\right]^{2+}$ complex mentioned above, the lack of luminescence in cells can be due to a quenching effect of the environment on the excited state of the compound. ${ }^{[10]}$ A technique that allows for precise quantification of the cellular uptake(i.e., ICP-MS or AAS) should be applied to ascertain this observation.

The relatively low ${ }^{1} \mathrm{O}_{2}$ production was unfortunately reflected in the phototoxic behaviour of the compounds.From these results emerges clearly the fact that, in the field of Ru(II) polypyridyl complexes as PSs in PDT, and more generally in the field of Ru- 
containing anticancer drug candidates, a lot has still to be done to understand the influence of the structure on the biological behaviour of the compounds. As mentioned earlier, a small variation of the structure can deeply affect the biological outcome of the system and the rationale behind it has to be still fully unveiled.

\section{Acknowledgements}

This work was financially supported by the Swiss National Science Foundation (Professorships $N^{\circ}$ PP00P2_133568 and PP00P2_157545to G.G), the University of Zurich (G.G), the StiftungfürwissenschaftlicheForschung of the University of Zurich (G.G.), the Novartis Jubilee Foundation (G.G and R.R.)and the UBS PromedicaStiftung (G.G. and R.R.). We thank Dr.JakobHeier from the Laboratory for Functional Polymers, Empa, Swiss Federal Laboratories for Material Science and Technology, for generous access to a near-IRfluorimeterand the Center for Microscopy and Image Analysis of the University of Zurich for access to state-of-the-art equipment. ${ }^{[10]}$ The authors thank Dr. Vanessa Pierroz for help with the cell experiments.

\section{References}

[1] R. Trondl, P. Heffeter, C. R. Kowol, M. A. Jakupec, W. Berger and B. K. Keppler, Chem. Sci. 2014, 5, 2925-2932.

[2] C. G. Hartinger, M. A. Jakupec, S. Zorbas-Seifried, M. Groessl, A. Egger, W. Berger, H. Zorbas, P. J. Dyson and B. K. Keppler, Chem. Biodivers. 2008, 5, 2140-2155.

[3] G. Sava, S. Zorzet, C. Turrin, F. Vita, M. Soranzo, G. Zabucchi, M. Cocchietto, A. Bergamo, S. DiGiovine, G. Pezzoni, L. Sartor and S. Garbisa, Clin. Cancer Res. 2003, 9, 1898-1905.

[4] A. Weiss, R. H. Berndsen, M. Dubois, C. Muller, R. Schibli, A. W. Griffioen, P. J. Dyson and P. Nowak-Sliwinska, Chem. Sci. 2014, 5, 4742-4748.

[5] C. Mari, V. Pierroz, S. Ferrari and G. Gasser, Chem. Sci. 2015, 6, 2660-2686.

[6] http://theralase.com/pressrelease/theralase-files-us-patent-application-increased-targeting-photo-dynamic-therapy/.

[7] T. Joshi, V. Pierroz, S. Ferrari and G. Gasser, ChemMedChem 2014, 9, 1419-1427.

[8] V. Pierroz, T. Joshi, A. Leonidova, C. Mari, J. Schur, I. Ott, L. Spiccia, S. Ferrari and G. Gasser, J. Am. Chem. Soc. 2012, 134, $20376-20387$.

[9] A. Frei, R. Rubbiani, S. Tubafard, O. Blacque, P. Anstaett, A. Felgenträger, T. Maisch, L. Spiccia and G. Gasser, J. Med. Chem. 2014, 57, $7280-7292$.

[10] C. Mari, V. Pierroz, R. Rubbiani, M. Patra, J. Hess, B. Spingler, L. Oehninger, J. Schur, I. Ott, L. Salassa, S. Ferrari and G. Gasser, Chem. Eur. J. 2014, 20, 14421-14436.

[11] T. Joshi, V. Pierroz, C. Mari, L. Gemperle, S. Ferrari and G. Gasser, Angew. Chem., Int. Ed. Engl. 2014, 53, $2960-2963$.

[12] C. Mari, V. Pierroz, A. Leonidova, S. Ferrari and G. Gasser, Eur. J. Inorg. Chem. 2015, DOI: 10.1002/ejic.201500602.

[13] N. J. Lundin, P. J. Walsh, S. L. Howell, A. G. Blackman and K. C. Gordon, Chem. Eur. J. 2008, 14, 11573-11583.

[14] E. Wachter, D. K. Heidary, B. S. Howerton, S. Parkin and E. C. Glazer, Chem. Commun. 2012, 48, 9649-9651.

[15] H. Ishida, S. Tobita, Y. Hasegawa, R. Katoh and K. Nozaki, Coord. Chem. Rev. 2010, 254, 2449-2458.

[16] R. Schmidt, C. Tanielian, R. Dunsbach and C. Wolff, J. Photochem. Photobiol. A 1994, 79, 11-17.

[17] M. C. DeRosa and R. J. Crutchley, Coord. Chem. Rev. 2002, 233-234, 351-371.

[18] S. Mathai, T. A. Smith and K. P. Ghiggino, Photochem. Photobiol. Sci. 2007, 6, 995-1002.

[19] V. r. Nardello, D. Brault, P. Chavalle and J.-M. Aubry, J. Photochem. Photobiol. B: Biology 1997, 39, 146-155.

[20] A. Leonidova, V. Pierroz, R. Rubbiani, J. Heier, S. Ferrari and G. Gasser, Dalton Trans. 2014, 43, 4287-4294.

[21] P. B. Merkel and D. R. Kearns, J. Am. Chem. Soc. 1972, 94, 1029-1030.

[22] I. Ott, C. Biot and C. G. Hartinger in AAS, XRF and MS Methods in Chemical Biology of Metal Complexes, Vol. (Ed. G. Gasser), Wiley-VCH Verlag GmbH \& Co. KGaA, 2014. 

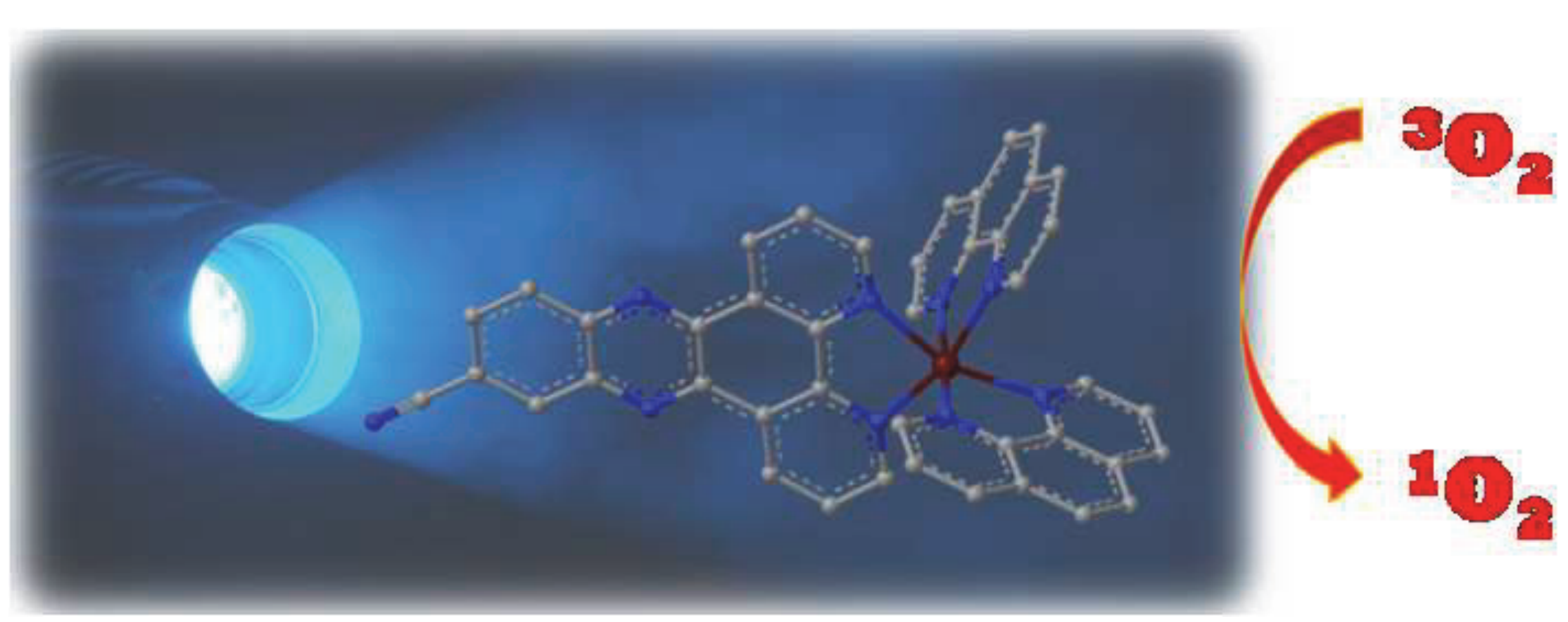

Graphical 